\title{
DOES PREFERENTIAL PAIRING OCCUR IN SECALE CEREALE $\times S$. MONTANUM TETRAPLOID HYBRIDS?
}

\author{
C. G. D. CHAPMAN* \\ Department of Agricultural Botany, The University College of Wales, Penglais, Aberystwyth, \\ Dyfed
}

Received 8.viii.83

\begin{abstract}
SUMMARY
Meiosis was examined in $F_{1}$ hybrids between Secale cereale and $S$. montanum where tetraploidy had been induced by the use of colchicine. The frequency of ring bivalents was higher, and the average size of multivalents lower, than a model assuming random pairing of chromosome arms predicts. This is interpreted as evidence of preferential pairing.
\end{abstract}

\section{INTRODUCTION}

Secale cereale and $S$. montanum differ from each other by the presence of two interchanges involving three chromosomes (Riley 1955). The diploid hybrid between them pairs normally at meiosis save for disturbances caused by the interchanges. Cells showing a chain of six chromosomes and four ring bivalents at metaphase I are not uncommon. However, in a wheat background i.e. in an octoploid Triticale with one set of chromosomes from S. montanum and one set from S. cereale, there is very little pairing between the two sets of chromosomes (Riley and Miller 1970). This is due to the activity of the $P h$ gene of wheat and indicates that there is a homoeologous rather than homologous relationship between the two genomes.

There are genes in rye which are antagonistic to the $P h$ gene of wheat (Miller and Riley 1972, Lelley 1976). It cannot be expected, therefore, that the hybrid tetraploid will behave like an allotetraploid. But as the two genomes are not identical it may well be that there will be some preferential pairing occuring. Any that does occur may enhance fertility, and would also tend to conserve the hybrid genotype in successive generations.

Tetraploid rye hybrids have been examined for preferential pairing by Rheimann-Philipp and Eichorn-Rohde (1970). They were unable to reach any firm conclusions, as although the frequency of large configurations was less than expected and that of the bivalents higher, they were unable to separate any effect of preferential pairing from failure to form multivalents due to low chiasma frequency.

Sybenga (1973) and Elci and Sybenga (1976) looked for preferential pairing in tetraploid rye hybrids using induced interchanges separate from those already existing between the species. By using a test cross they were able to examine the types of gametes produced and show that in at least one case the ratio of the three possible types differed significantly from that expected. This was interpreted as evidence of preferential pairing.

* Present address: International Board for Plant Genetic Resources, Food and Agriculture Organisation, 1776 F Street N. W., Washington, D.C. 20437, U.S.A. 


\section{THE MODEL}

In the present material there was no single interchange that might have been used after the fashion of Sybenga (1973). Instead an indicator was sought in the number of ring bivalents per cell. The proportion of these would be expected to rise if preferential pairing occured. Rod bivalents could not be included as these might represent larger configurations that had degraded due to low chiasmata frequency.

A theoretical model of ring bivalent frequency can be constructed by assuming that pairing between homologous chromosome arms occurs at random, and that all chromosome arms are paired. For a single noninterchanged set of homologous chromosomes cells showing a ring quadrivalent and cells showing two ring bivalents should occur in a ratio of $2: 1$ (Timmis and Rees 1971). The frequencies and configuration patterns expected by extending this over the four non-interchanged chromosome sets are shown in table 1 (i).

TABLE 1

Configurations and ratios expected from complete and random pairing in a tetraploid rye hybrid

(i) Non-interchanged chromosomes

\begin{tabular}{lcc}
\hline \multicolumn{1}{c}{ Configurations } & $\begin{array}{c}\text { Frequency } \\
\text { (81 possible } \\
\text { arrangements) }\end{array}$ & $\begin{array}{c}\text { Total number of } \\
\text { ring bivalents }\end{array}$ \\
\hline 4IV & 16 & 0 \\
3IV+2II & 32 & 64 \\
2IV+4II & 24 & 96 \\
IV+6II & 8 & 48 \\
8II & 1 & 8 \\
Total & & 216 \\
Average & & 2.6667 \\
\hline
\end{tabular}

(ii) Interchanged chromosomes

\begin{tabular}{lccc}
\hline \multicolumn{1}{c}{ Configurations } & $\begin{array}{c}\text { Frequency } \\
\text { (729 possible } \\
\text { arrangements) }\end{array}$ & $\begin{array}{c}\text { Total number of } \\
\text { ring bivalents }\end{array}$ & $\begin{array}{c}\text { Total number of } \\
\text { chromosomes involved } \\
\text { in the largest } \\
\text { configuration }\end{array}$ \\
\hline XII & 224 & 0 & 2688 \\
X+II & 96 & 96 & 960 \\
VIII + IV & 96 & 0 & 768 \\
2VI & 80 & 0 & 480 \\
VIII + 2II & 48 & 96 & 384 \\
VI+ IV+II & 96 & 96 & 576 \\
3IV & 16 & 0 & 64 \\
VI+ 3II & 24 & 72 & 144 \\
2IV+2II & 36 & 72 & 144 \\
IV+4II & 12 & 48 & 48 \\
6II & 1 & 6 & 2 \\
Totals & & 468 & 6258 \\
Averages & & $0 \cdot 6667$ & 8.5844 \\
\hline
\end{tabular}




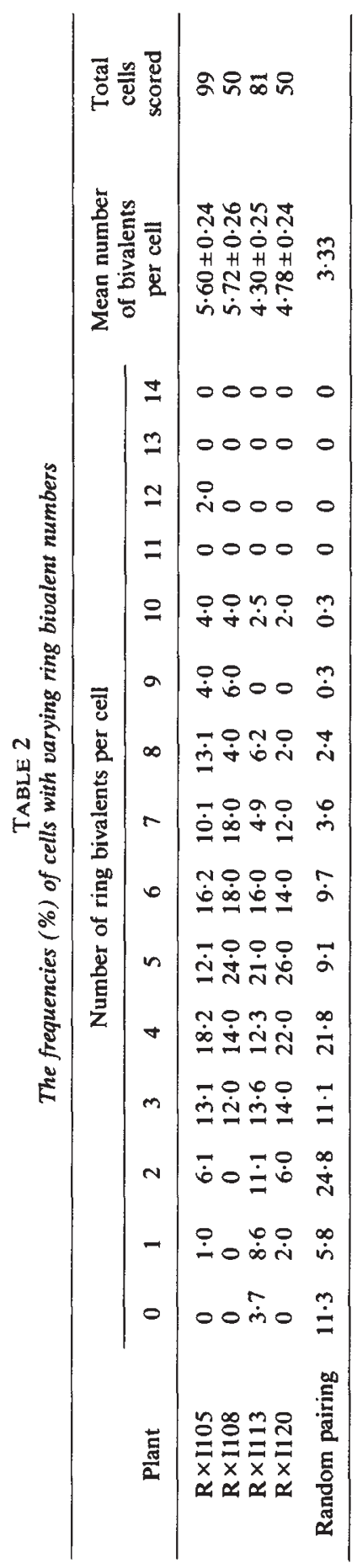


For the interchanged chromosomes the models of Linnert (1962) and Sybenga (1973) were extended to include two interchanges on three chromosomes. As there are six sets of homologous arms, each of which can pair in three ways, there are $3^{6}=729$ ways in which the interchange group can be arranged. The different configurations, and the number of each type are set out in table 1 (ii).

These separate contributions can be combined to give expected frequencies for cells with each number of ring bivalents (table 2). This gives an expectation of a mean of 3.33 ring bivalents per cell.

\section{MATERIALS AND OBSERVATIONS}

Four lines of $S$. montanum, I105, I108, I113 and I120, were crossed with the $S$. cereale variety, Rheidol. At metaphase I in meiosis all the diploid $F_{1}$ hybrids showed a chain of six and four ring bivalents. Some hybrid

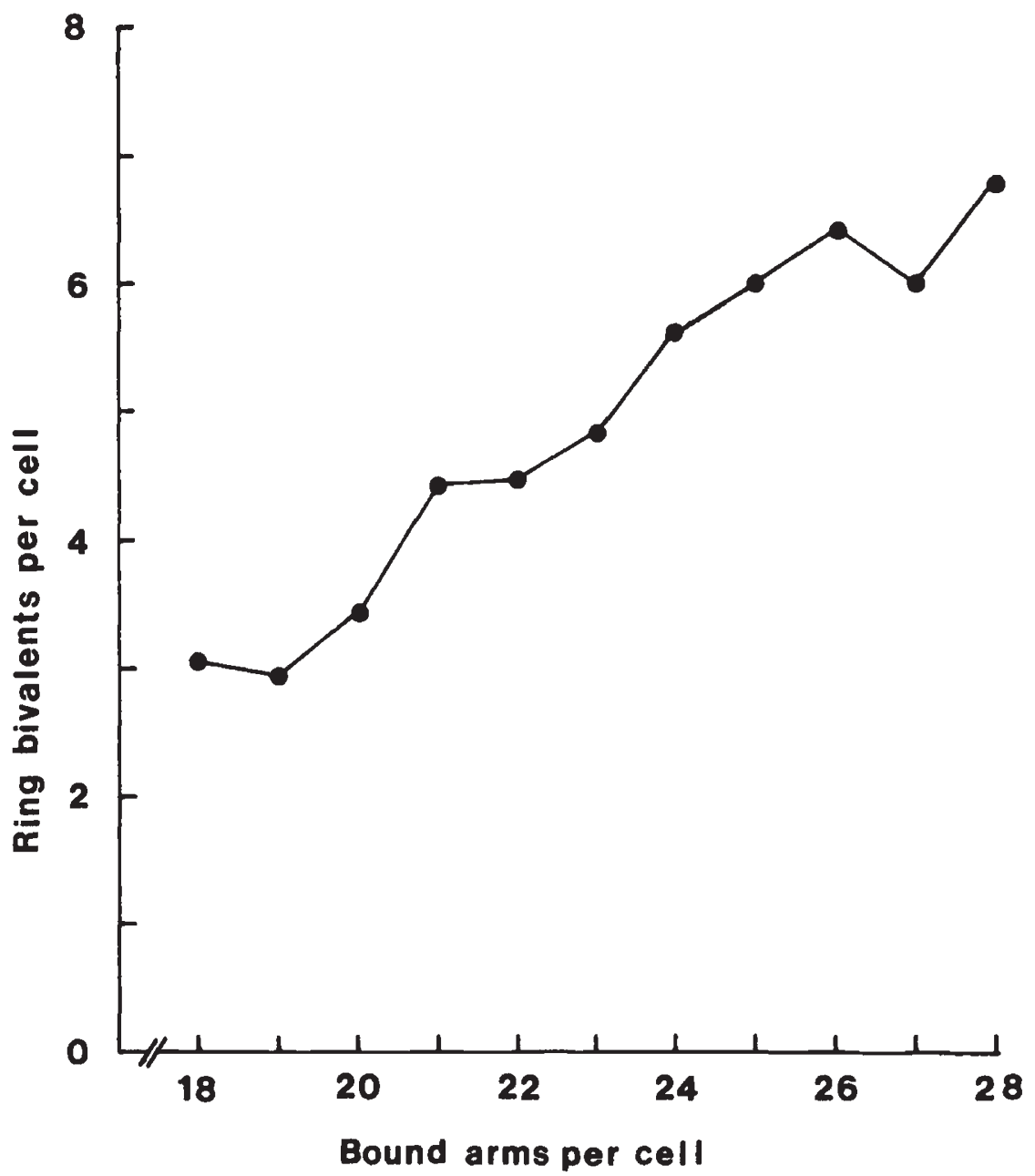

FIG. 1. The relationship between ring bivalent number and the number of bound arms per cell 
seedlings were treated with colchicine to induce tetraploidy. Meiosis was examined in detail in a single tetraploid plant of each of the four hybrids and the frequency of ring bivalents per cell scored.

The pattern for each line is shown in table 2. A standard error for each mean has been calculated on the assumption that the distributions approximate normality. In each case the mean is higher than expected showing that there are more ring bivalents per cell than the model predicts. It is likely that these values are an underestimate, as the model assumes that all chromosome arms are bound. In practice the observed numbers of bound arms varied from 28 down to 18 . If the results from all four plants are merged, a positive relationship can be seen between the number of bound arms and the number of ring bivalents (figure 1 ). This indicates a true mean value of about $6 \cdot 2$ ring bivalents per cell if all arms are bound (table 3 ).

TABLE 3

Configurations observed in 20 cells with 27 and 28 bound arms

\begin{tabular}{|c|c|c|c|c|c|c|}
\hline \multirow[b]{2}{*}{ Number of cells } & \multicolumn{6}{|c|}{ Configurations } \\
\hline & II & IV & VI & VIII & $\mathrm{X}$ & XII \\
\hline 1 & 12 & 1 & & & & \\
\hline 2 & 10 & 2 & & & & \\
\hline 4 & 8 & 3 & & & & \\
\hline 3 & 6 & 4 & & & & \\
\hline 3 & 4 & 5 & & & & \\
\hline 1 & 2 & 6 & & & & \\
\hline 3 & 5 & 3 & 1 & & & \\
\hline 1 & 3 & 4 & 1 & & & \\
\hline 1 & 6 & 2 & & 1 & & \\
\hline 1 & 4 & 3 & & 1 & & \\
\hline Averages & $6 \cdot 2$ & $3 \cdot 4$ & $0 \cdot 2$ & $0 \cdot 1$ & & \\
\hline \multirow{2}{*}{$\begin{array}{c}\text { Expected } \\
\text { (random pairing) }\end{array}$} & $3 \cdot 33$ & $3 \cdot 11$ & $0 \cdot 38$ & 0.20 & $0 \cdot 13$ & $0 \cdot 31$ \\
\hline & $\begin{array}{l}\text { Number of } \\
\text { Number ex } \\
\chi \chi\end{array}$ & $\begin{array}{l}\text { vith a c } \\
.87\end{array}$ & Iration & $\begin{array}{l}\text { or larger } \\
01\end{array}$ & $\begin{array}{c}6 \\
18.2\end{array}$ & \\
\hline
\end{tabular}

Similarly, in fully paired cells the size of the largest multivalent is too small. An average of 8.58 chromosomes per largest multivalent is expected but the observed average is about 5 , with no configurations larger than 8 (table 3).

\section{Discussion}

This study shows that there are between 1 and 2.4 too many ring bivalents per cell in these hybrids than can be explained by random pairing of the chromosome arms. For cells that are fully paired there are about 3.2 too many ring bivalents. There are also too few chromosomes in the average largest multivalent in cells with complete pairing. This is strong circumstantial evidence for preferential pairing, but is not beyond criticism. 
The model assumes that pairing of chromosome arms is independent. But Timmis and Rees (1971) proposed that there is a restriction on pairing at pachytene in autotetraploid rye. They showed that there were 1.7 too many ring bivalents in autotetraploid ryes derived from inbred lines. This pairing restriction could partly explain the higher numbers of ring bivalents found here, but preferential pairing would still be required to account for the residue. There is also the problem that extrapolating from cells with 28 bound arms per cell to those with fewer may not be satisfactory. It could be that completely paired cells have higher bivalent numbers in part because it is easier to realise small configurations than large ones.

Ideally for this sort of study a direct comparison between the tetraploid hybrid and autotetraploids of both parent lines should be made, as Lewis (1980) has done for Lolium. In this case however the presence of interchanges, would have confounded the comparison.

As $S$. montanum and $S$. cereale chromosomes cannot be distinguished morphologically at meiosis the only certain way of determining if preferential pairing occurs would be by identifying and observing the segregation of genetic markers as Breese and Thomas (1977) have done in Lolium.

Because of these uncertainties it is not proposed to calculate the amount of preferential pairing thought to occur. But if the fully paired cell typically contains mainly bivalents and quadrivalents it must be quite high.

Acknowledgments. I should like to acknowledge the financial and moral support of the Agricultural Research Council and Dr Gareth Evans respectively.

\section{REFERENCES}

BREESE, E. L. AND THOMAS, A. C. (1977) Uniformity and stability of Lolium multiflorum $\times$ L. perenne allotetraploids. Proc. 8th Eucarpia Congress, pp. 155-180

ELCI, S. AND SYBENGA, J. (1976) Incomplete preferential pairing in a tetraploid Secale hybrid carrying translocations. Multivalent configuration frequencies and marker segregation. Genetica, 46, 177-182

LELLEY, T. (1976) Induction of homoeologous pairing in wheat by genes of rye suppressing chromosome 5B effect. Can. J. Gen. Cytol., 18, 485-489

LEWIS, E. J. (1980) Chromosome pairing in tetraploid hybrids between Lolium perenne and L. multiforum. Theor. Appl. Genet., 58, 137-143

LINNERT. G. (1962) Untersuchungen an Hemiploiden nachkommen Autotetraploider. $Z$. Vererb. lehre, 93, 389-398.

MILLER, T. E. AND RILEY, R. (1972) Meiotic chromosome pairing in wheat rye combinations. Genetica Iberica, 24, 241-250

REIMANN-PHILIPP, R. AND EICHHORN-RHODE, H. (1970) Uber die Beziehungen von Fertilitat und Modus der Chromosomenpaarung bei Tetraploiden, fur drei Chromosomen strukturbeterozygoten Bastarden aus der Kreuzung Secale cereale $\times$ Secale montanum. Theor. Appl. Genet., 40, 99-105

RILEY, R. (1955) The cytogenetics of the differences between some Secale species. J. Ag. Sci., 46, 377-383

RILEY, R. AND MILLER, T. E. (1970) Meiotic chromosome pairing in Triticale Nature 277, $82-83$

SYBENGA, J. (1973) The effect of reciprocal translocations on segregation and multivalent formation in autotetraploids of rye, Secale cereale. Genetica, 44, 270-282

TIMMIS, J. N. AND REES, H. (1971) A pairing restriction at pachytene upon multivalent formation in autotetraploids. Heredity, 26, 269-275 